\title{
Zona Sagrada: Una Lectura Mítica
}

Pedro Páramo (1955) de Juan Rulfo y Zona sagrada (1967) de Carlos Fuentes, aunque no sean estrictamente novelas de la revolución mexicana, son descendientes directos de este movimiento." Mientras que los autores principales de este movimiento, como Mariano Azuela y Martín Luis Guzmán, usaban métodos aparentemente documentales para recrear la realidad de la revolución que ellos mismos experimentaron, Rulfo y Fuentes han empleado mitos para acercarse a este momento histórico para ellos pasado, si no terminado.

En su ensayo La nueva noveld hispanoamericana, Fuentes resume 10 que él considera el aporte principal de la novela de la revolución no sólo a la interpretación de una realidad histórica determinada sino a la evolución de la novela hispanoamericana. El considera esa contribución una de "ambigüedad crítica":

Porque en la dinámica revolucionaria los héroes pueden ser villanos y los villanos pueden ser héroes. No sólo hay origen y permanencia fatal en el origen; hay, por fin, un destino en movimiento. No sólo hay unas relaciones dictadas fatalmente desde el siglo xvi; hay un

* Cito Pedro Páramo por la edición del Fondo de Cultura Económica (México, 1955); Zona sagrada, por la de Siglo Veintiuno (México, 1967); La nueva novela bispanoamericana, por la de Joaquín Mortiz (México, 1969); El laberinto de la soledad, por la de Fondo de Cultura Económica (México, 1959); Corriente alterna, por la de Siglo Veintiuno (México, 1967); Edipo. Mito y complejo, por la traducción del Ateneo (Buenos Aires, 1953). Los trabajos de Emir Rodríguez Monegal sobre Rulfo y Fuentes se han publicado respectivamente en $E l$ Nacional, de Caracas ("Relectura de Pedro Páramo", octubre 26, 1969) y en Número, de Montevideo ("El mundo mágico de Carlos' Fuentes", julio-septiembre, 1963). La entrevista del mismo crítico con Carlos Fuentes está recogida en El arte de narrar, del primero, publicado por Monte Avila (Caracas, 1968). El trabajo de Severo Sarduy está recogido en Escrito sobłe un cuerpo, publicado por Sudamericana (Buenos Aires, 1969). 
tumulta (...) en el que los seres de ficción, como todos los hombres, viven sus momentos de luz y sus instantes de sombra. En la literatura de la revolución mexicana se encuentra esta semilla novelesca: la certeza heroica se convierte en ambigüedad crítica, la fatalidad natural en acción contradictoria, el idealismo romántico en dialéctica irónica. (p. 15)

Aunque Azuela y Guzmán estaban demasiado envueltos en esa realidad para "penetrar en sus propios hallazgos" (como dice Fuentes) o para desarrollar sus intuiciones, no dejaron de echar las bases para una interpretación novelística futura de la realidad mexicana. En el mismo capítulo de su libro, Fuentes señala que en Pedro Páramo, Juan Rulfo da un paso más adelante al mitificar:

las situaciones, los tipos y el lenguaje del campo mexicano, cerrando para siempre $\rightarrow$ con llave de oro- la temática documental de la revolución. Rulfo convierte la semilla de Azuela y Guzmán en un árbol seco y desnudo del cual cuelgan unos frutos de brillo sombrio: frutos duales, frutos gemelos que han de ser probados si se quiere vivir, a sabiendas de que contienen los jugos de la muerte. No sé si se ha advertido el uso sutil que Rulfo hace de los grandes mitos universales en Pedro Páramo. Su arte es tal, que la trasposición no es tal: la imaginación mítica renace en el suelo mexicano y cobra, por foutuna, un vuelo sin prestigio. (...) todo este trasfondo mítica permite a Juan Rulfo proyectar la ambigüedad humana de un cacique, sus mujeres, sus pistoleros y. sus víctimas y, a través de ellos, incorporar la temática del campo y la revolución mexicanos a un contexto universal. (p. 16)

En parte, estas observaciones de Fuentes en el capítulo, "Revolución y ambigüedad", se apoyan en observaciones hechas por Octavio Paz en el artículo, "Paisaje y novela en México", que estál recogido en Corriente alterna (1967). En ese texto, ya Paz vincula el viaje de Juan Preciado a Comala con el mito bíblico del Paraíso Perdido: al volver a su pueblo natal, Juan Preciado está regresando al Edén:

Pero el personaje de Rulfo regresa a un jardín calcinado, a un paisaje lunar, al verdadero infierno. El tema del regreso se convierte en el de la condenación; el viaje a la casa patriarcal de Pedro Páramo es una nueva versión de la peregrinación del alma en pena. 
Simbolismo - ¿inconsciente — del título: Pedro, el fundador, la piedra, el origen, el padre, guardián y señor del paraíso, ha muerto; Páramo es su antiguo jardín, hoy llano, seco, sed y sequía, cuchicheo de sombras y eterna incomunicación. El Jardín del Señor: el Páramo de Pedro. Juan Rulfo es el único novelista mexicano que nos ha dado una imagen - no una descripción- de nuestro paisaje. Como en el caso de Lawrence y Lowry, no nos ha entregado un documento fotográfico o una pintura impresionista sino que sus intuiciones y obsesiones personales han encarnado en la piedra, el polvo, el pirú. Su visión de este mundo es, en realidad, visión de otro mando. (p. 18)

La realidad geográfica de México que tenía un papel central y a la vez simbólico en las obras de Azuela y de Guzmán, se convierte en metáfora en Pedro Páramo. En su ensayo, Paz interpreta la imagen de México que surge de la novela de Rulfo como un desierto, un jardín muerto, el purgatorio. A esa imagen bíblica que evoca Paz, agrega Fuentes el mito gricgo que él descifra en Pedro Páramo. La búsqueda del padre que es la misión principal de Juan Preciado al regresar a Comais, aparece vinculada a la peregrinación de Telémaco en busca de Ulises. El guía de Juan Preciado en el camino a Comala, ese Abundio que desaparece tan súbitamente, es también hijo de Pedro Páramo: uno de los que él ha sembrado por ahí; por lo tanto, es medio hermano de Juan. En cierto sentido, es también un doble de Juan: al matar a Pedro Páramo parece estar también cumpliendo la venganza de éste. Ambos son Edipos, aunque uno solo es parricida. El punto de vista mítico sobre Pedro Páramo ha sido desartollado, a la zaga de Paz y de Fuentes, por el joven crítico peruano Julio Ortega, en un ensayo de La cantemplación y la fiesta (1969), y por Emir Rodríguez Monegal en un trabajo publicado en El Nacional, de Caracas (1969). Este último estudia la novela de Rulfo como una búsqueda del padre y de los orígenes: una búsqueda última de la identidad que concluye con un particidio real y otro simbólico. En un trabajo bastante anterior, Rodríguez Monegal había indicado cómo estos antiguos mitos griegos, bíblicos y hasta indígenas tenían una importancia central, aunque entonces no visible para toda la crítica, en la obra de Fuentes anterior a Cambio de piel y Zana sagrada (ambas de 1967). Ya en Aura (1961) y en pasajes de sus primeras novelas y cuentos, Fuentes aprovecha esos elementos míticos que dan una dimensión excepcional a su realismo.

Un enfoque mítico similar podría aplicarse a Zona sagrada. Esta novela, aunque aparentemente muy distinta a Pedro Páramo, tiene elementos. 
comunes con ella. Es claro que en la superficie no pueden ser más distintas. En tanto que la novela de Rulfo se ubica en un pueblo mexicano, perdido en la sierra y cubierto de polvo, Zona sagrada se mueve brillantemente de la sociedad cosmopolita de la Ciudad de México a la de Roma et environs. Sin embargo, gracias a sus vínculos profundos con mitos de carácter universal, las dos novelas superan las diferencias superficiales y revelan su hondo parentesco. Así como el tema central en Pedro Páramo es la búsqueda de la identidad a través de la búsqueda del padre, el tema central de la novela de Fuentes es la búsqueda de la identidad del hijo de Claudio Nervo, búsqueda que él realiza perversamente a través de su madre. Edipo vuelve a vivir en el México de ambos autores, pero también reviven los viejos mitos mexicanos. Es ésta fusión de mitos que proyectan una imagen más compleja de la realidad de México y de la revolución mexicana, lo que me gustaría examinar ahora por medio de una lectura mítica de Zona sagnada.

Se podría decir de Zona sagrada lo que ha dicho Rodríguez Monegal de Pedro Páramo: allí "la tradición asume las máscaras de lo contemporáneo, el tema universal se viste de los accidentes de lo regional". La novela de Fuentes se abre con un capítulo irónicamente titulado, en inglés para subrayar más la ironía y la cita: "Happily Ever After". El lugar es la playa italiana de Positano. Aquí el protagonista, que se llama Guillermo Nervo, pero todos llaman Mito (de Guillermito), está bebiendo un Campari con su amigo y tal vez amante italiano, Giancarlo Adelphi, al que se refiere el narrador como "tú", en la mejor tradición del Nouveau Roman. Este "tü" sugiere inmediatamente un espejo, un doble. La presencia de Giancarlo no se siente realmente sino como reflexión del protagonista-narrador. Más tarde comprendemos que Giancarlo es algo más que un doble para el diálogo: es también un hermano simbólico de Mito. La relación entre ambos no es sólo homosexual sino también incestuosa; su verdadera significación se revela hacia el final del libro, en el capítulo, "Suertes de Naipe", cuando Mito entra en el cuarto de hotel de su madre en Roma y la encuentra haciendo el amor con Giancarlo. Entonces, éste lo llama: "Hermano".

El tema del mito de Ulises es también presentado en el primer capítulo que funciona como prólogo y epílogo del libro. Desde la mesa a que están sentados en la playa de Positano (Poseidón, a propósito), los dos 
jóvenes pueden ver la isla de las famosas sirenas que en la leyenda como en la Odisea trataron de seducir a Ulises. Así como el tratamiento aparentemente lineal de la acción en la novela revela un enfoque irónico, el título del primer capítulo ("Y vivieron felices", habría que traducirlo) sugiere un último capítulo. En realidad, ese primer capítulo es el último, y por lo tanto la forma general de la novela es cíclica.

También el mito de Ulises es tratado irónicamente aquí. Fn tanto que en la versión homérica, Ulises regresa de la guerra y de sus viajes, reconquista a su mujer y su reino, y parece haber alcanzado la felicidad, Fuentes sugiere alarmantemente en el primer capítulo de Zona sagrada que Ulises era un gran mentiroso y que las cosas no pasaron como Homero las cuenta. Para esta interpretación, Fuentes se basa en otra versión, "verdadera y no abreviada", escrita por Apolodoro, novelista de la decadencia. El asegura haber descubierto esta versión leyendo el libro de Robert Graves, The Greek Mytbs según ha contado en una entrevista de 1966 con Rodríguez Monegal. Afirma Fuentes allí: "Lo importante de los mitos vivos, no de lo mistificado, sino de lo mitificado, es que en realidad nunca se cierran". Fuentes continúa diciendo que, según Apolodoro, lo que realmente le pasó a Ulises es que regresa de la guerra hecho un viejo y se pone a contar sus historias a la mujer y el hijo hasta volverlos locos. Telémaco se siente obligado a reiniciar los viajes del padre. En la isla de la hechicera Circe descubre que tiene un hermano, un doble, Telégono.

$Y$ para completar los destinos y las sustituciones, Telémaco se acuesta con Circe, se convierte en el marido de Circe. $\mathrm{Y}$ ahora es Telégono el que prosigue las peregrinaciones, los viajes que lo tienen que llevar a ese desolado y rústico reino de Itaca, donde se encuentra esa vieja pareja, Ulises y Penélope. Penélope ve entrar por la puerta al joven Ulises, el que vio partir a la guerra. Ergo, Penélope y Telégono se escabechan a Ulises, lo matan y Telégono ocupa el lecho de su padre. Bueno, esto es un poco el marco mítico de esta historia, Zona sagrada. (El arte de narrar, pp. 133-134)

Por supuesto que Fuentes no reproduce este mito, paso a paso, en su novela. Al contrario: como hace Rulfo en Pedro Páramo, aunque tal vez más deliberadamente, Fuentes emplea sólo ciertas analogías: Mito y Giancarlo corresponden a la configuración de Telémaco-Telégono; Claudio Nervo es una Penélope-Circe; México es a Itaca como Roma es a la isla de Circe. Constantemente ciertas imágenes de la novela se están refiriendo 
al mito. Y pot supuesto, la imagen clave, del mito, la Odisea o el viaje -no sólo en el tiempo y también en el espacio sino, simbólicamente, el viaje de la niñez a la edad madura y de ésta a la vejez, de la vida a la muerte, o vice-versa el eterno viaje y la eterna búsqueda que es la vida (y la muerte) - es aquí también, como en Pedro Paramo, la imagen clave de Zona sagrada.

III

Lo que se busca es posible encontrar Sófocles: Edipo Rey.

Uno de los epígrafes de Zoma sagrada es, significativamente, la primera línea del primer capítulo de Rayuela: "Encontraría a la Maga?" Según ha destacado Fuentes (en su ensayo sobre la nueva novela hispanoamericana, p. 70), està pregunta entrega "la clave de esa búsqueda inconclusa, "increíble", que, cerrada antes de escribir el libro, Oliveira re-presenta en la ceremonia de la escritura de un libro". Esta búsqueda inconclusa que, como del mito de Ulises, no tiene fin, es la "esencia" de Zona sagrada. Es como el deseo de Mito de poseer, y finalmente destruir, y por lo tanto sustituirse a su madre. Pero ese deseo no habrá de realizarse nunca. Por eso, debajo de la máscara de brillante cosmopolitismo, la novela de Fuentes refleja una búsqueda desesperada: la de una identidad.

Zona sagrada ha sido calificada por uno de sus mejores criticos, Severo Sarduy, como "una parábola de la posesión". A lo largo de toda la novela, Mito trata de poseer vicariamente a su madre, principalmente al convertir su departamento en una "zona sagrada", un vientre simbólico, o como dice Sarduy:

un recinto análogo al materno, cámara a la que se regresa como a la infancia, a lo irrecuperable: una selva estilo 1900 lograda a partir de Claudia, de una vieja fotografía del apartamento de Sarah Bernhardt. . .

La fotografía de la Bernhardt era regalo de la madre y con ella decora centralmente Mito ese departamento que se levanta contra la casa materna: esa zona tival que él quisiera poseer pero que se le escapa de la misma manera que se le escapa la madre. Otras formas de posesión son el préstamo del sweater de cachemira gris perla, o la contemplación reiterada de las películas de la madre, o esas conversaciones en que la 
hace hablar de cosas íntimas, o esos abrazos que siempre terminan en recriminaciones, o ese constante mendigar de la atención de ella. Todos estos actos tienen un hondo sentido masturbatorio, y en algunos casos implican una masturbación real.

El incesto es, naturalmente, tabú pero eso no importa. Porque lo que él realmente quiere no es el cuerpo de la madre sino su rostro. $\mathrm{O}$ como escribe Sarduy:

...esa perfección que su hijo quiere atraer, incorporarse, apular, como para llenar su rostro vacío, ese a que el Otro materno no ha delegado su ser.

Ese rostro, esa máscara que es la cara de la madre, y que oculta por lo tanto también la identidad de él, es lo primero que él descubre cuando ella lo viene a raptar, de niño, a arrancárselo de las manos de los abuelos paternos donde ella lo había dejado abandonado:

Me apretó contra ella y me dijo que era mi madre y yo levanté la mirada y encontré, más entonces por ser la primera vez y ser la sorpresa, mi propio rostro de niño convertido en otra cosa... (p. 16).

En un último intento de poseer la identidad de la madre, de hacerla suya, Mito se viste con sus ropas y se pone sobre su rostro el maquillaje de ella: "el rito del travestismo lo va devolviendo a sí mismo, a la recuperación de su imagen", observa Sarduy, que agrega como conclusión: "En el disfraz hay una adoración implícita del Otro; en la conversión del travestí una conjura para que desaparezca, un exorcismo que reclama su muerte". Pero como Claudia Nervo, el original, la autoridad, está todavía viva, toda transformación es ridícula, es una irrisión. Disfrazado como su madre, Mito es (dice Fuentes) un:

...príncipe de burlas, muñeco embarrado de cosméticos, seco árbol de Navidad cuajado de bisuterías, perro famélico que ya no puede sostenerse sobre los tacones altos, gigantescos, zancos... (pp. 186187)

Mito no puede, no quiere, actuar. Está inmovilizado por el conflicto entre su adoración y su odio por su madre. Psicológica, simbólicamente, es impotente. $\mathrm{O}$, dicho de otra manera, su existencia es la del deseo insatisfecho. Este "mensaje" se reitera a lo largo de la novela y en formas 
distintas. Uno de los pasajes más destacados es aquél en que Mito contempla la posibilidad del acto definitivo del asesinato y, aún, del canibalismo: el acto más completo posible de posesión. Pero su reflexión lo conduce a rechazarlo:

Yo sólo tengo nostalgia de ella: abulia, desaparición, ¿Todo ha de ser deseo del pasado del porvenir? $\mathrm{Y}$ ella es dueña del eterno presente. Esa es la verdadera lucha. (pp. 176-177)

Y como Claudia, la inmortal diosa blanca de que habla Graves, gana esta lucha ya que ni desaparece ni muere, es Mito el que muere simbólicamente al convertirse en un perro: una metamorfosis que esconde un suicidio. La elección de un perro es doblemente significativa porque Mito solía tener perros que humillaba, castraba o dejaba morir en la peligrosa supercarretera que se llama "El Periférico", y también porque ese animal, fiel y obsequioso era considerado por los griegos como uno de los más inferiores. Mito alude al viejo mito de la mujer hechicera que, como Circe en la Odisea, convierte a los hombres en animales, cuando le grita a Giancarlo (su Telégono) :

Penélope no existe, Ulises no existe, todos terminamos con Circe, nada más, convertidos en puercos... (p. 183)

La muerte simbólica de Mito como perro que se presenta en el último capítulo (que no es el último sino el penúltimo, ya que la novela empieza con el último) puede ser interpretada como una literalización de la expresión coloquial: muerte de perro. En El laberinta de la soledad, Octavio $\mathrm{Paz}$ vincula esta expresión con el concepto que tiene el indio mexicano de la muerte. Para éste, "la muerte es un espejo que refleja las vanas gesticulaciones de la vida". Más adelante observa Paz: "Muerte de cristiano a muerte de perro son maneras de morir que reflejan maneras de vivir".

Al "morir" como un perro, Mito refleja su actitud canina hacia Claudia, que es evidente en toda la novela. Su relación con su madre es equivalente a la que tienen sus perros con él. Por eso, de acuerdo con esa tradición mexicana de la muerte de que habla Paz, la muerte simbólica de Mito, su humillación final, no está separada de su vida tal como aparece en la novela, sino que es una prolongación de la vida, y aún más, una fase, una transformación en una serie de transformaciones. Y para conformarse con la idea del "ciclo infinito", de que también habla 
Paz, la humillación final de Mito, o su "muerte", no es final, sino una en la serie de humillaciones que continuarán indefinidamente ya que la forma del libro es cíclica.

Es interesante observar que mientras que en Pedro Páramo la muerte está en el centro de la novela y es la conclusión inconclusa o la prolongación infinita del destino de Juan Preciado y todos los otros personajes, la humillación ocupa ese mismo lugar en Zona sagrada. $Y$ no se trata sólo de la humillación de Mito sino la de todos los que son tocados, o que reflejan, a Claudia Nervo, y en definitiva la humillación latente de ella misma. Como Juan Preciado, que busca a su padre no sólo para conocetlo (y conocerse) sino también para vengar las humillaciones que su madre sufrió a manos del padre, y su propia herededa humillación, Mito también es incapaz de realizar el acto que habría permitido concluir esa búsqueda. De la misma manera, Giancarlo equivale a Abundio. Así como éste ("borracho, incoherente, arrastrado por una fatalidad que no entiende", según escribe Rodríguez Monegal) habría de matar a Pedro Páramo, al padre, Giancarlo llega a poseer a Claudia y por lo tanto a estar en situación de humillarla; posibilidad que él presenta a Mito:

... ¿y si yo logro humillarla?, ¿y si yo obro en tu nombre?, ¿y si yo la rompa y la transformo y te la ofrezco en toda su debilidad, detrás de sus palabras agresivas y su falsa fuerza?... ¿y si yo te entrego a tu madre verdadera, desnuda, sin máscara, ofendida, revelada al fin por un hombre imaginado que le ofrece la última sorpresa: la sorpresa de que, contra todas las apariencias, yo no la reflejo?, ¿y si tu madre acepta al fin que se huye de la soledad para encontrar la humillación?... (p. 183)

Al crear un paralelo entre la humillación en Zona sagrada y la muerte en Pedro Páramo, no excluyo el hecho de que ambos elementos juegan importantes papeles en, las respectivas novelas. Así, Pedro Páramo, el gran humillador de hombres y mujeres, es finalmente humillado por la indomable y loca Susana San Juan. Aquí se podría encontrar un paralelo con la posible humillación de Claudia Nervo por parte de Giancarlo. Lo que quiero decir es que la muerte es el destino en Pedro Páramo en tanto que la humillación que es una suerte de muerte espiritual, es la última destrucción en Zona sagrada.

Volviendo a Giancarlo, su papel en la novela de Fuentes no sólo sirve para completar el ciclo de Ulises sino también el coincidente de Edipo. Porque el mito de Ulises, tal como lo cuenta Apolodoro, es probablemente 
una reinterpretación de la leyenda de Edipo. El padre tan esperado, el marido al que se sacrifica la fidelidad, se convierte en la versión de Apolodoro en un insoportable y autoritario anciano. Telégono mata y reemplaza a Ulises como Edipo mata y reemplaza a Layo. Quisiera mostrar cómo este múltiple mito funciona en términos psico-sociológicos no sólo en Pedro Páramo sino también en Zona sagrada.

IV

El Estado es una imagen agrandada del individuo.

Platón, citado por Samuel Ramos, El perfil del bombre

Por lo general, el mito de Edipo es entendido como símbolo del vínculo incestuoso entre la madre y el hijo, pero (como observa Erich Fromm) debe ser entendido:

como la rebelión del hijo contra la autoridad del padre en la familia patriarcal; (...) el matrimonio de Edipo y Yocasta es sólo un elemento secundario, sólo uno de los símbalos de la victoria del hijo, que se apodera del lugar del padre, y de todos sus privilegios.

La cita de Fromm (que tomo de Patrick Mullahy: Edipo. Mito y complejo, 1953, p. 261) distingue nítidamente entre su enfoque y el de Freud. Para éste, el complejo de Edipo es el resultado del conflicto entre las pasiones irracionales de la infancia y la "realidad" tal como está representada por los padres y la sociedad. From, en cambio, ve esta misma neurosis y el famoso complejo como:

expresiones de una lucha entre la tendencia legítima del hombre a la libertad, la independencia, y las conveniencias sociales que frustran la lucha del hombre por su felicidad e independencia. (p. 267)

De acuerdo con esta interpretación, Otto Rank, uno de los primeros discípulos de Freud, discutió la posibilidad de que el conflicto edípico sea no sólo una lucha del niño para liberarse de la autoridad paterna sino una lucha del individuo para liberarse de su papel biológico. Según escribe, este conflicto es "la lucha entre el 'ego' individual que se cree 
inmortal, y el 'ego racial' personificado por la 'ideología sexual' que renuncia a la inmortalidad individual en favor del matrimonio y de los hijos". (Mullahy, p. 201).

La repugnancia de Mito hacia la sexualidad femenina y su rechazo total, que estarían basados en una fijación materna y el terror del incesto, según la teoría freudiana clásica, estarían también basados en el miedo de la mortalidad que la mujer representa. E1 siguiente pasaje de Zona sagradd, en que Mito piensa en lo que son las mujeres debajo de su sedosa superficie, expresa esta doble repugnancia de la sexualidad y la mortalidad:

...tubo de excrecencias, mucosas blandas, pulmones teñidos de tabaco, pus agarrotado en el fondo del paladar, ostras podridas, pezones supurantes, coágulos de sangre menstrual, náusea de la carroña eternamente abierta, heridas sin cicatriz, intestinos hinchados, gases verdes, bilis espesa, largo túnel de mierda y huevecillos infestados y placentas amenazantes... (p. 70)

Pero la sexualidad femenina representa la mortalidad no sólo por el proceso de corrupción que se realiza en su cuerpo, sino porque es a través de la mujer que se nace a este mundo, a esta vida que es el camino de la muerte. El último pasaje de Zona sagrada revela este sentido:

hermanos, tardamos en abandonar el vientre de nuestra madre, aunque ella pujaba por parirnos: creíamos que salir de ella, abandonarla, era morir. Nucve meses es un siglo. Y él, ahora, en brazos de ella, no querrá abandonar la vida, querrá permanecer enterrado en ella y temerá la muerte como los dos, antes de nacer, temimos la vida.

Yo no.

Esa es mi victoria. Un perro sabe morir sin sorpresa. (pp. 190191)

De aquí deriva la necesidad mito-psicológica del protagonista de una Zona sagrada, una matriz que no lo expulse, una gruta encantada que lo donserve eternamente vivo y lo salve de la temporalidad. El lugar que, de acuerdo con otra solución del mito griego, es la isla de las Sirenas en donde Ulises sucumbe y donde permanece eternamente joven, eternamente sensual. $O$, en el mito inca, el lugar a donde los Incas regresan eternamente para renovar sus energías. Ambos mitos (el de las Sirenas, el Inca) son apuntados por Fuentes en su novela. 
Esta concepción de la vida como una especie de muerte (o de purgatorio, como la presenta Rulfo), de la vida como una separación entre el desea y la satisfacción (la vida de Mito), la vida como un pasaje de lo que fuimos a to que seremos, podría vincularse a lo que dice Paz en $E l$ laberinto de la soledad. Allí estos conflictos se estudian no sólo en el contexto de la condición humana de los mexicanos sino de todos los hombres en general. Pero resumir y discutir estas ideas en el contexto no sólo de la obra de Paz sina de las novelas de Ruilfo y de Fuentes nos llevaría demasiado lejos del tema de este trabajo.

Lo que sí quisiera agregar con respecto al conflicto edípico es que no sólo los hijos en Pedro P'áramo y Zona sagrada lo ilustran en los términos que han definido Otto Rank y Erich Fromm, sino que también lo ilustran los padres. No sólo los hijos y las mujeres de Pedro Páramo buscan liberarse de él, ese super-ego que los humilla y los aplasta, sino también lo hace Pedro Páramo que, al abandonarlos, rechaza su 'ego racial'. Su interés vital está centrado en su propio poder, por lo tanto en su inmortalidad. Su "machismo" es el vehículo por medio del cual no sólo realiza su potencia sexual sino alcanza el poder socio-económico y hasta político. Y cuando al fin acepta por primera vez su papel de padre y recoge a Miguel Páramo, acepta también su mortalidad. Lo destaca una frase que dice al enterarse de la muerte de Miguel, como observa Rodríguez Monegal:

No es, por eso, casual que a la muerte de Miguel, Pedro sienta que empieza a expiar sus muchos crímenes.

- "Estoy comenzando a pagar. Más vale empezar temprano, para terminar pronto".

En la novela de Fuentes, Claudia Nervo ocupa el lugar de Pedro Páramo. Si éste tepresenta al déspota mexicano clásico, el terrateniente, el caudillo que todo lo aplasta y que lleva la máscara del machismo para imponer su poder absoluto (véase lo que dicen tanto Samuel Ramos como Paz sobre esta máscara), Claudia Nervo es un déspota de este tiempo, la superstar de la sociedad de consumo, que lleva su brillante máscara hecha en Hollywood para dominar, para someter y para destruir. Los valores norteamericanos son impuestos por ella a un México sometido. 


\section{V \\ Ya sabes que yo cargo con el honor de la patria. . . Ni te cuento: antes la imagen de México era Pancho Villa y ahora soy yo. Claudia Nervo.}

Así como Pancho Villa se levantó contra la injusticia del México de Porfirio Díaz, así Pedro Páramo (que fue antes un hijo cuyo padre habían asesinado) y así Claudia Nervo (que fue también una hija) se levantaron contra la injusticia. La tiranía de Pedro Páramo comienza como un acto de venganza contra los asesinos de su padre y como una afirmación de sus discutidos derechos de propiedad. Claudia representa la liberación de la mujer mexicana. Ella continúa no sólo a Sor Juana (esa precursora olvidada o desconocida) sino a La Pintada, de Azuela, esa soldadera que en Los de abaja se rebela contra el papel acordado a la mujer mexicana y no acepta ser una Malinche, como diría Paz. De hecho, en una de sus películas Claudia hace el papel de soldadera. La secretaria de ella comenta a Mito el bien que Claudia ha hecho por la mujer mexicana:

Puede que tu mamá nos haya hecho un poquito más libres, un poquito mejores, a todas. ...Tu madre ha demostrado que en México una mujer puede vivir de acuerdo con su propia moral y su propia fantasía. (pp. 109-110)

Pero así como Pedro Páramo se levantó contra la injusticia sólo para perpetrar injusticias, Claudia se levanta contra el machismo y contra la pretensión del macho a la superioridad, para convertirse en una suerte de macha castradora. Abandona al padre de Mito, que se convierte en una sombra, una débil voz de reproche, como la madre en Pedro Páramo. Su primer encuentro con el hijo es una suerte de violación ya que apareció súbitamente y con violencia lo arranca del cariño y de la protección de los abuelos paternos: un acto violento de separación comparable al del nacimiento. $Y$ buscando la inmortalidad, como Pedro Páramo, rechaza a su hijo para que el mundo del cine no sepa que es una madre de cincuenta años. Al vengarse de la humillación impuesta por el machismo a la mujer mexicana, Claudia usa a los hombres, los empequeñece, los viola en un sentido simbólico (viola su dignidad), y los abandona -como 
el conquistador español violó al indígena, como el macho mexicano viola a la mujer.

Claudia - que es también Circe, la hechicera de los mitos griegoses "la diosa indígena de la muerte, la fertilidad y la inmundicia", como dice Fuentes en la novela, es TTlazoltéotl, una versión femenina y vengativa de Jehová que aniquila el machismo destructivo de Pancho Villa para sustituirlo por otro no menos violento. $\mathrm{Y}$ cuando cede a su mortalidad y se entrega a Giancarlo, ella también (como Pedro Páramo al enamorarse de Susana San Juan) será humillada y destruida.

La relación fatal que Paz observa en México entre el hombre (que está cerrado) y la mujer (que está rajada) se vuelve a perpetrar una vez más aquí en Zona sagrada, aunque la relación parezca ahora invertida. La serpiente mexicana continúa devorando su cola. Juan Rulfo metaforizó ese ciclo mortal mexicano en términos de tragedia griega y de apocalipsis bíblico: al final de sui novela, Pedro Páramo se derrumba como una pila de piedras; la civilización misma se derrumba. Claudia Nervo se rebela no sólo contra el imperialismo sexual de los machos sino también contra el económico de la sociedad de consumo: sus chistes sobre recuperar a Texas y batir a los yankis en su propio juego aluden claramente a esta otra forma de machismo. Pero el problema de ella es como el de Pedro Páramo: al triunfar se vuelve imperialista. Por un lado, perpetúa la sumisión económica de México (es decir, convierte a su hijo en perro), y por otro lado, asume todo lo que es falso en la realidad de su patria: esa brillante fachada internacional de la Ciudad de México. Claudia Nervo ha sustituido como mito a Pancho Villa porque ella es la falsedad de la Revolución Mexicana. Ella, la diosa de la vida y la muerte, da vida sólo para matar. Mito Nervo, en su rebelión frustrada, en la deformación de su sexualidad, es la revolución congelada.

SuZANNe JiLL Levine

New York University 